September -2009

\title{
Exploring Blended Learning for Science Teacher Professional Development in an African Context
}

\author{
Bopelo Boitshwarelo \\ University of Botswana
}

\begin{abstract}
This paper explores a case of teacher professional development in Botswana, where a blended learning solution was attempted. The analysis of the implementation environment reveals deficiencies in policy, schools (workplaces), and training providers. The paper concludes with three recommendations: 1) Schools should support on-going teacher learning in the workplace and should manage ICT resources for use by both teachers and students; 2) Government should support participatory and localised learning and institutionalise ICT access and use; and 3) Training providers should use blended methods and should model good ICT practices. The author also notes that change is needed in the culture of teaching and learning so that ongoing, situated, participatory, and collaborative approaches are accepted. Finally, collaboration between the training providers and the schools is necessary as is a change in beliefs about the use of ICTs in education.
\end{abstract}

Keywords: Blended learning; workplace-based learning; ICTs; Africa, teacher professional development

\section{Towards Blended Learning Solutions for Africa}

The rapid advances in information and communications technologies (ICTs) have acted as a catalyst for educational transformation in recent years the world over (Nichol \& Watson, 2003). Africa is also attempting to take advantage of this technological revolution in order to make strides in the advancement of education (Selinger, 2002; Isaacs et al., 2004; Shrestha, 2000). For the continent, particularly sub-Saharan Africa (SSA), these technologies offer tremendous hope towards meeting the present day educational challenges of lack of access to quality higher education. Traditionally, open and distance learning (ODL) methods, particularly print and radio/audio, have been used to expand this access. In particular, teacher education, both preservice and in-service, has benefited from this arrangement. However, these traditional methods of ODL, while having their merits, are not adequate to meet the high demand for quality teacher education as they lack the attributes of quality that tend to characterize the more modern technologies. Therefore there is growing consensus that SSA needs to explore the potential of 
technology-mediated education if it is to survive on the global competitive stage (Selinger, 2002; Unwin, 2005; Mackintosh, 2005). An examination of the literature on ICTs for education reveals that one trend for improving quality in education, particularly continuing and distance education, involves blended learning (Lewin, 2000; Unwin, 2005). Blended learning refers to designing and delivering the right content in the right format using the right mix of media (Debande \& Ottersten, 2004).

\section{Blended Learning in Africa}

The limited ICT infrastructure in Africa means that it is not feasible to run full-scale online programmes even if it is the best thing to do pedagogically. The ICT infrastructure problem, which is widespread across the continent, is characterized by limited availability and low-quality services. Isaacs et al. (2004) identify low Internet bandwidths, very limited telephone connections, and negligible computer ownership as serious and common problems across Africa. Most of the ICT infrastructure is limited to capital cities and major centres and is unavailable to the great majority of rural and remote area dwellers, leading to uneven access (Sagna, 2005). Therefore blended learning approaches have been recommended as the most efficient way to tap into the power of ICTs (Unwin, 2005). In combination with traditional methods of education delivery, it is possible that viable blended learning programmes could be developed and executed quite efficiently. In this regard, a number of initiatives or at least discussions in SSA are evident in the literature (for example, Patterson, 2005; Kruger \& Spamer, 2006; Seleka et al., 2006; Leary \& Berge, 2007; Schachter, 2005, Kok \& Merz, 2004). However, only a few of the initiatives (such as Ayoo \& Lubega, 2008) offer any comprehensive analysis of the instructional design process. There is a need for more explicit accounts of designing, developing, and implementing blended learning solutions in the context of Africa. The literature on blended learning is becoming awash with good exemplars in this regard.

\section{Blended Learning Pedagogy}

Several researchers, such as Boyle (2005), have sought to explicate theoretical models that will aid the development of pedagogically robust blended learning solutions. This paper will analyse two such articles in a bid to demonstrate how the design of blended learning environments could be made less tacit. These two models or frameworks take into consideration the complexity of blended learning environments especially in terms of the decision-making that informs their design and the factors that impact their implementation and how these should be viewed as intertwined.

The first model is suggested by Kerrs and De Witt (2003). They offer a general conceptual framework that guides the elements to be included, their relative weight, and their sequence in the blend. They use what they term the 3-C model, which conceptualizes learning as having three components, namely content, communication, and construction (which plays a facilitative and guiding role in the learning process). While they point out that not all the components need to be present for learning to take place, they argue that their collective presence leads to richer and more meaningful experiences. Each of these components can be delivered in different media 
formats. The learning goals and specific objectives can help determine their relative weight (in terms of time to be spent by learners). For example, content would dominate if the knowledge to be learned consists of facts or rules to be recalled. In terms of the medium of delivery, they recommend that it should match the learning task. However, according to this model, it is not just the learning task match that should determine the delivery system but also the cost. Cost in this case is twofold: It should be considered from the institution's point of view, mostly in monetary terms, and also from the learner's perspective, which in this case is defined in terms of not just money but also time demands and cognitive effort. For instance, while face-to-face delivery, in the context of ODL, may be a pedagogically viable option to deliver certain learning activities, it may become costly for learners in respect of time and money required to travel.

Thus, in brief, the parameters of Kerrs and DeWitt's model suggest that blended learning solutions should take into account the following: learning goals and objectives, characteristics of the content, target group, and situation/institutional demands. Essentially, a blended learning environment needs to “... address the demands of a given learning situation” (p. 111).

The second model is presented by Alonso et al. (2005). Realising a gap exists as far as the insufficiency of teaching principles for e-learning, Alonso and others argue that there is a need for pedagogical guidelines for instructional practice. They say these guidelines should target analysis, design, development, support, and management of e-learning materials pedagogically. Their model takes into account the three basic learning theories of behaviourism, cognitive theory, and constructivism. Their view on these theoretical perspectives on learning is that they are interdependent and have a capacity to be combined to "...build instructional design heuristics" ( $p$. 219).

This instructional design model is based upon the following premise:

...training should enable learners to apply the concepts learned at their workplace and evaluate the results... [ and that] the aim is for learners to be engaged by the E-learning contents to the extent that they get to understand things that they did not comprehend before. This will make them ready to practice and take action to perform new activities (p. 222).

Subsequently, this will lead them to make reflections and to extend their knowledge to newer understandings and better practices.

To achieve this, the model makes use of the systematic development of instruction, which is composed of seven stages: analysis, design, development, implementation, execution, and evaluation. Underlying this process is an emphasis on the following:

- content structure, which is determined by the different information types and performance goals; 
- cognitive processes, with a focus on factors that can enhance cognitive activity such as using visual formats to improve perception, using other media to reduce cognitive overload, or using concept maps to enhance coding; and

- collaborative activities, which are characterized by the co-participation in activities, the promotion of community spirit, and the facilitative role of the instructor.

The components identified in the blended learning menu are face-to-face teaching, online interactions, and self-paced online learning, which in the context of training facilitate direct training, coaching, and self help respectively. Similar to the Kerrs and DeWitt model, the nature of the blend is determined by learning objectives, the target learners, the content structure, and the available technologies. This model also places emphasis on the key role of managing the blended learning process.

These models exhibit similarities and complementary differences. Therefore taken together they form a robust theoretical basis for blended learning solutions with the major emphasis being on systematic development of instruction, which recognizes types of content and desired learning outcomes and matches them with appropriate strategies to ensure that learners learn and apply the acquired skills in a reflective way. The selection of an appropriate blend is determined by a number of parameters, such as objectives, types of content, availability of technology, and the demands of each delivery system on both the institution and the learner.

It is against this background that this paper will explore blended learning solutions in the context of Africa. The paper seeks to extend understanding of blended learning through the explication of some of the processes discussed above using a case study. The specific details of this paper are discussed next.

\section{Aim and Rationale of the Paper}

The specific aim of this paper is to give an account of a case study that used a blended learning approach in the context of science teacher professional development ${ }^{1}$. It explains the instructional design process, and it analyses factors surrounding the implementation of the innovative part of the blended learning menu. The paper will demonstrate the complexity of ICT interventions in traditional methods and perhaps give a better theoretical and practical insight into how blended learning solutions play out in authentic African environments.

As far as the rationale is concerned, there was little, if any, evidence of research specifically targeted at determing the potential of the available ICT capacity in Botswana, particularly in secondary schools, in facilitating teacher workplace-based learning. Thus, the author investigated whether teachers can benefit from the available infrastructure for their ongoing professional development and the issues surrounding such. This rationale will become clearer in the discussion of the context below and in subsequent sections of this paper.

\footnotetext{
${ }^{1}$ The case study formed part of the author's $\mathrm{PhD}$ research (Boitshwarelo, 2007).
} 


\section{Context of the Paper}

The specific context of this paper is an in-service training (INSET) programme at the University of Botswana, which offers professional development of secondary school science teachers in Botswana. To situate this specific context, a broad background, which touches on the aspects that are relevant to this study, is described briefly below.

\section{Botswana}

Botswana is a landlocked country situated in Southern Africa with a population estimated at about 1.8 million people, covering over 580,000 square kilometers of land. Relative to a majority of SSA countries, Botswana has impressive economic credentials and political stability. These offer a unique environment in which the potential for the use of ICT for development in general, particularly educational development, can be explored and tapped (Boitshwarelo, 2007).

\section{Educational Developments in Botswana}

With regard to access to basic education, Botswana has achieved the "10 year Basic education for all" for the current generation of young people with the latest statistics indicating that about $100 \%$ of all school-age children are enrolled in schools (Republic of Botswana, 2005). While access is almost $100 \%$ at the basic education level, with admission to senior secondary schools expected to rise to the same percentage in the next several years, the same cannot be said about tertiary education. This is because tertiary education is not able to adequately absorb the increasing output from secondary schools. Conventional modes of tertiary education, in particular, are not coping with the demands of education and training for manpower development in Botswana (Mokaeya, 2005). This problem is twofold. First, only a limited number of places for diploma and bachelor's degrees exist for students who have successfully completed their secondary education. Second, those who are in the workplace and want to further their education, from diplomas to bachelor's degree levels or from bachelor's degrees to postgraduate level qualifications, including professional development programmes, have to compete with their peers for access to the limited places.

\section{ICT Developments in Education}

The government of Botswana is fully committed to the widespread adoption of ICTs in all sectors of society, including education. While the uptake of ICTs and the e-readiness of the education sector has been very low (Ministry of Communications, Science and Technology, 2005), the recently approved National ICT Policy, Maitlamo, promises to alleviate this problem as it aims to transform Botswana into an ICT-driven economy. The policy with regards to education makes a number of recommendations for programmes and projects that will be carried out in order to successfully implement ICT across all levels of education in Botswana. If these noble initiatives become a reality then the use of ICT to increase access to and quality of education at all levels of education could be realised. These recommendations build upon the Revised National Policy on 
Education (RNPE) of 1994 (Republic of Botswana, 1994), which recommends ICT literacy for all secondary school children.

\section{The University of Botswana}

The University of Botswana, a national institution funded by government, is committed to the use of ICTs for innovative teaching and to the opening up of opportunities for non-conventional learners. Over the past several years, the University has developed its technological infrastructure including the acquisition of a learning management system, WebCT, to advance one of its aspirations to develop a student-centred, intellectually stimulating, and technologically advanced teaching, learning, and research environment (University of Botswana, 2004). This commitment is carried out by the Centre for Academic Development (CAD) through the Educational Technology Unit (ETU), which is charged with promoting "appropriate and innovative uses of educational technology." One of the key performance areas (KPA) of CAD is as follows: "Extend access to higher education through the utilization of Information and Communications Technologies within the framework of lifelong learning and open learning." This KPA augments another mandate of "extending the university's programmes to non-conventional learners," which is carried out by the Centre for Continuing Education. While the infrastructure is obviously not adequate, considerable progress has been made with a substantial number of courses (not programmes) having an online presence.

It is against this background of the growing presence of ICT infrastructure and the commitment to educational innovation in the context of open and lifelong learning that this study was carried out.

\section{The INSET Programme for Science Teachers at UB}

The INSET programme, which was the target of the case study, is offered by a department at the UB, whose mission is to provide instruction and research in order to produce high calibre computer studies, mathematics, and science teachers and thus contribute to national manpower development. This department also aims to provide opportunities for the professional development of serving teachers through improving and sustaining the efforts of its INSET section.

With regard to the latter function of professional development, the department usually runs its national INSET workshops every April/May school vacation for about two or three days for senior secondary science teachers on behalf of the Ministry of Education's (MoE) Department of Teacher Training and Development (DTT\&D), In-service Training Unit (University of Botswana, 1997). This training is aimed at the ongoing professional development of in-service teachers and is meant to continually improve the quality of science teaching. These workshops are run separately for biology, chemistry, physics, mathematics, and computer studies. The workshops aim to broaden the teachers' pedagogical content knowledge (PCK) and increase their skills in learner-centred science education (Thijs, 1999). This approach is premised on the idea that initial teacher training is usually insufficient to ensure that teachers carry out their roles effectively as they have inadequate skills to integrate subject matter, pedagogy, and teaching context ( Gess- 
Newsome, 1999) and as such they need to develop PCK over the course of their careers (Shulman, 1986). During the workshops, participants gain theoretical knowledge and also, more importantly, they engage in hands-on activities, such as developing lesson plans and conducting microteaching sessions with peers. They also discuss their plans to implement the workshop outcomes in their classrooms once they are back at their schools. The teachers are expected to implement the skills they have acquired and discuss them with their peers. The trainers sometimes pay visits to the schools after completion of the workshops to offer support and to monitor the progress of the teachers.

A developmental study that targeted this INSET programme was carried out by the author to find out how the existing ICT capacity at the UB and in the country could be blended with the traditional method in order to improve it. This study was exploratory in nature and it used a developmental qualitative approach in the form of design-based research (DBR) methodology (Brown, 1992; Collins et al., 2004; Bell, 2004). DBR is carried out through extended, iterative theory-based interventions that explore learning in authentic contexts. These interventions, usually in the form of technological artefacts, are tested in particular situations, thus unpacking the issues surrounding their use (Design-Based Research Collective, 2003). The details of the study follow in the next section.

\section{Blended Learning in Action: A Case Study Analysis}

\section{Analysis}

The first stage of the study was to investigate the INSET programme described above, particularly its shortcomings and whether they could be addressed through online means. The main shortcoming identified in the INSET programme was the fact that while the teachers who were trained in the workshops value the knowledge and skills imparted to them, they receive no support when they apply these workshop outcomes in their schools. Since these workshops are used to teach innovative methods, teachers need a substantial amount of both expert and peer coaching before they can confidently and effectively apply the acquired skills. As mentioned by Alonso et al. (2003) "...training should enable learners to apply the concepts learned at their workplace and evaluate the results...," which in this case was lacking. From interviews with the concerned trainers and from previous research (particularly Thijs, 1999) the following reasons for this gap were identified:

1. There is a lack of enthusiasm once teachers return to their respective schools.

2. Peer coaching and collaboration within the school setting is very limited due to time and other constraints. Thijs also observed that in Botswana collaboration in the form of classroom observation and discussion does not fit with teachers' preferences or the school context. Additionally because only one or two teachers per school attend the workshop, it is difficult for the remainder to assume ownership of the innovation.

3. There is a geographical separation between workshop participants once they are back in their respective schools, and therefore there is very little continued interaction, if any. 
4. Because of time and cost constraints there is little or no follow-up by the INSET staff at the UB.

Given these challenges, an online learning environment that facilitates continued interaction between teachers who have attended the same workshop and their trainers was conceptualized to facilitate distributed and situated learning and to form a community. This online interaction would be blended with the face-to-face workshop training and the printed material handouts. The online environment was envisaged with the understanding that although most teachers (as was the case with those at the workshop) do not have Internet access in their homes, they have some workplace access, with a few exceptions. It was acknowledged that this access is very limited but perhaps enough to be put to use for this purpose. As stated previously the idea was to investigate to what extent the available ICT-capacity in these schools could be used to support an online community of a select number of biology teachers.

\section{Design}

The goal was to design the online environment as an intervention in the existing INSET programme. The environment was called Biology Teachers Online (BTO) as it was targeting biology teachers specifically ${ }^{2}$. The desired outcomes of BTO are outlined below:

- individual participation by teachers in the form of receiving and reading messages;

- information exchange between participants;

- $\quad$ social, professional, and academic interaction amongst teachers;

- expert advice from trainers at UB-INSET; and

- completion of collaborative tasks.

Towards this end a comprehensive design statement was developed, which included details on the following: conceptual background of BTO and its aim, technical and administrative information, design, structure, and media elements used, instructional approach and tasks, implementation, and evaluation. Essentially, BTO was designed to run in WebCT and to act as a space for collaboration, supported by other features that were meant to assist in scaffolding the social experience.

\section{Development}

BTO was developed according to the design details described above in WebCT at UB. The learning environment was developed in close collaboration with ETU (alluded to earlier). ETU assists academic staff in the production and use of a growing variety of educational technologies to improve their teaching and to engage students in more active learning. It manages and facilitates the use of WebCT, which is its primary delivery system. For this reason the staff at

\footnotetext{
${ }^{2}$ The programme for the different subjects (biology, chemistry, physics and mathematics) usually runs cocurrently once a year in different venues. The researcher/author chose biology teachers because he shares a similar background and could easily relate to the issues of biology teaching.
} 
ETU played a significant role in the iterative development of BTO: creating the course shell, advising on the use of WebCT tools, and creating accounts in the course for participants. The INSET staff members were asked to conduct a review of the learning environment, especially in terms of its pedagogical elements and its content before it could be implemented. Although there was not much feedback, the environment was approved. The figure below shows part of the BTO homepage after completion.

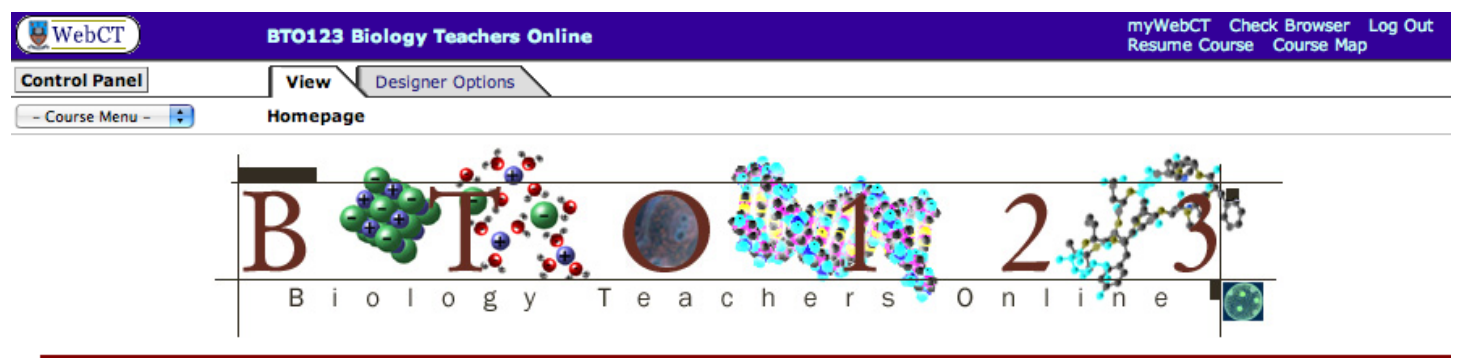

\section{WebcT Course}

\section{Welcome to Biology Teachers Online}

Welcome to Biology Teachers Online (BTO). My name is Bopelo Boitshwarelo and I, together with Professor Tembo and possibly other staff members at DMSE-INSET, will be facilitating your interactions and collective learning in this learning environment. BTO is a socio-technical learning environment (i.e. a technical space that allows social interaction between people learning together) and will be used as an intervention in your usual DMSE-INSET programme.

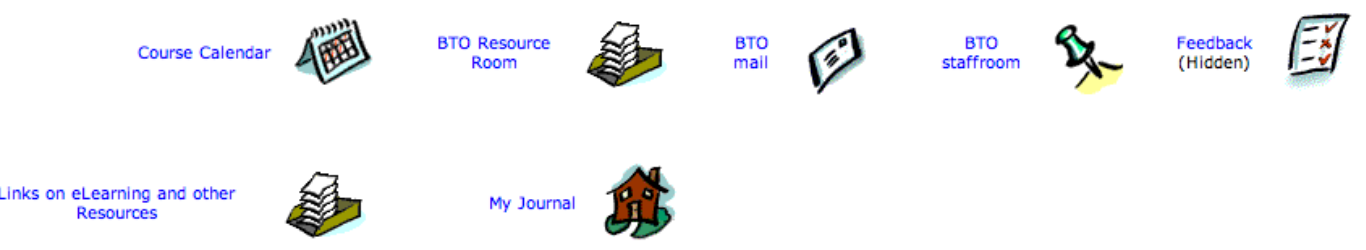

Figure 1. Part of the BTO homepage.

\section{Implementation}

BTO was implemented in 2006 for a period of about three months between May and August. This implementation followed an INSET workshop whose theme was the development and implementation of process skill in biology teaching. Only 18 of the expected $27^{3}$ schools were represented, each by one teacher, and three resource persons facilitated the workshop. The following activities for teachers were included in the workshop:

- carrying out exemplar biology practical work sessions and reflecting on them together;

- discussing issues, such as changing trends in curriculum, instructional practices, and practical work; and

- refining draft worksheets on process skills.

\footnotetext{
${ }^{3}$ At the time of the research there were 27 government (public) senior secondary schools existing across the country.
} 
Concerning the draft worksheets, the intention was that the teachers should take these worksheets back to their respective schools, share them with their colleagues, and pilot-implement them with their students. They would then be able to share their experiences with colleagues from elsewhere and give feedback to their trainers at UB INSET. BTO was brought in to facilitate this activity, leading to a blended learning solution, which consisted of the following elements:

- workshop presentation of structured content, carrying out of practical activities, and live interaction among participants;

- printed material in the form of worksheets and other handouts;

- facilitation of the after-workshop interaction of participants.

As part of the training workshop programme, an introduction to online communities of practice and their value for professional teacher development was presented to all participants. Furthermore, there was a thorough discussion of how the BTO intevention would be integrated into the training. Although feedback from the teachers about the perceived value of BTO was positive, the common problem reported in most schools was limited access to the Internet, with three of the schools represented reportedly not having connectivity. The participants, who were all computer literate and who used computers in their work environment occassionally for administrative purposes, were shown how to access and use WebCT. Unfortunately, the Internet at the venue, the Media Centre for the MoE, was not available on the day the demonstration and practical activity were to be conducted. Therefore, those who faced problems accessing the BTO environment depended on the notes given to them and a demonstration by the researcher during school visits.

Since this was a research project and participation was voluntary, only 10 of the 18 teachers decided to take part in the online intervention. However, even the other teachers who did not agree to participate had access to BTO in case they wanted to be lurkers or retrieve any resources from the online environment. Of the three trainers, only one, who was the main player, volunteered to participate in the intervention. The data collected during the implementation stage came in these forms:

- participation data related to visits logged in and messages read or sent,

- questionnaire and interview data from teachers and ICT coordinators,

- observations during school visits by the researcher.

Reflective meetings were also held with the INSET people at the UB. Retrospectively, some officers in the MoE were interviewed to get insights into the policy dimension of the implementation environment. The outcomes of the implementation are discussed below. 


\section{Evaluation/Outcome}

\section{Enactment process and its outcomes.}

This section analyses the outcome of the implementation of BTO. Upon returning to their respective schools the teachers were expected to complete the first online activity, which was intended to determine the accessibility, usability, and sociability of BTO and to familarize the participants with the environment (Salmon, 2002). However a month passed without any evidence of activity in BTO. A visit was made to all of the participants; the round trip to the schools concerned covered 1,800 kilometres. From the questionnaire and interviews held with teachers, three themes emerged as to why they had not accessed BTO:

1. limited or no access to the Internet in schools,

2. time constraints due to various engagements during the school day, and

3. failure to access BTO for technical reasons.

After this visit there was some degree of activity in terms of access but still at a minimal level. By the end of the intervention period only five of the teachers logged into BTO and their combined total access episodes were nine. All five participants who accessed BTO entered the discussion forum and read (or at least opened) the messages posted mostly by the researcher. However, only three of the participants posted a total of four messages to the forum. The remainder of the messages originated with the researcher while the trainer never accessed the environment. Thus, overall, there was a paucity of involvement by the teachers and the trainer. A second visit at the end of the intervention period was essentially for debriefing purposes. It was also used to administer a retrospective questionnaire as well as to obtain verbal reflections by the teachers, where possible.

\section{Individual teacher participants.}

Data on individual teachers' experiences with BTO implementation was synthesised to develop an understanding of how their engagement contributed towards framing the enactment process and outcome. The data revealed that the teachers who participated in this research did so seemingly out of interest and a positive attitude towards the innovation. However, participation was very low, and this was attributable to the lack of time to do so, the lack of adequate and convenient access to the Internet, and the lack of activity within BTO. Internet access was the biggest challenge in schools not only because of the limited number of Internet-connected computers but also because of the limited times it was available to teachers. Therefore having analysed the teachers' involvement, it seemed that it was not the teachers' attitudes or unwillingness per se but rather it was the constraints in their workplaces, i.e., their respective schools, that led to their low involvement. 


\section{School environment.}

The school ICT environment played a major role in shaping how these teachers got involved in this intervention. An investigation of the school environment, particularly data from schools' ICT coordinators, was helpful in obtaining a broader understanding of the issues surrounding ICT access in the workplace by teachers in Botswana. There is a serious shortage of ICT facilities, particularly the Internet, for teacher use in schools. This problem is aggravated by the way the limited ICT resources are managed: Internet connections are available in a limited number of places in the school and at limited times. Moreover, the quality of connectivity is very poor due to narrow bandwidths. While there is a general belief that ICT has the potential for developing positive educational outcomes there is very little in practice to support the rhetoric. There seems to be a relatively narrow view of this potential, with the dominant use of ICTs being that of accessing educational resources and transmitting information but with very little use related to the collaborative and participatory dimension.

This situation is not a school-level problem; it has systemic influences. While government schools might exercise some degree of autonomy, in terms of day-to-day management of resources and activities, they operate under policy guidelines and regulations of the MoE. Therefore the MoE's provision of ICT infrastructure to schools, and the rationales for doing so, affords or constrains learning opportunities for teachers in the workplace.

\section{Policy environment.}

The policy environment in which this intervention was conducted is complex and this paper can not do justice to it. A detailed analysis is offered in Boitshwarelo (2007). However, a brief description of the ecological influence of policy will be presented briefly. The RNPE and the National ICT policy documents, alluded to above, recognise the importance of ICT in the school curriculum and recommend adequate facilities in schools so that students can acquire ICT skills. While the policies recognise the importance of teachers acquiring ICT skills, less emphasis seems to be placed on the role of ICTs as tools for ongoing, interactive, and participatory TPD. This probably originates from a predominantly centralised approach to training, which emphasises the acquisition of knowledge and skills. The MoE sponsors and/or carries out INSET activities for all teachers in government schools and to that end it has built regional education centres around the country. Therefore most of the resources, like ICT facilities, are concentrated in these centres for teachers to use when they come for INSET activities, but there are very few resources in schools. The ICT facilities in these centres are usually inadequate and the level of support to users is low. On the other hand, the ICT facilities in schools are primarily meant for teaching activities and not for TPD purposes. Therefore, while there is growing awareness of the potential of ICTs for effective TPD, the reality is that this is currently not being harnessed as the existing policies do not reflect adequate strategies for optimal use even at school level. 


\section{INSET provider.}

Other issues that significantly shaped the enactment of BTO had to do with the organisation that provided the INSET programme. In particular, issues of capacity, organizational structure, training approach, and commitment were identified as significant in determining how the intervention proceeded. In addition, the issues and challenges related to introducing innovation featured prominently as there seemed to be resistance to the intervention. The limited availability of time and resources also made it difficult to properly initiate the teachers into the innovation.

\section{Discussion and Conclusions}

The aim of this paper was to explore blended learning solutions in the context of Africa. In particular, the paper sought to explicate the pedagogic process of creating a blended learning solution and implementing it through a case study of teacher professional development in Botswana. The introduction of BTO to the INSET programme was essentially an attempt to use a blended learning approach for more effective training (Debande \& Ottersten, 2004; Boyle, 2005). The purpose of this particular blend was to ensure that the traditional face-to-face method, which is acquisitive and static in nature, was enriched by BTO (an online method), which is participatory and collaborative in nature and could facilitate ongoing learning that is situated in the real school setting. In terms of the models introduced earlier (Kerrs \& De Witt, 2003; Alonso et al., 2005), the workshop and its associated print materials (handouts) facilitated the acquisition of content (both at the knowledge and skills levels). On the other hand, the online intervention BTO was meant to support and enhance communication and collaboration in a temporally and spatially independent way. This intervention was seen not only as pedagogically appropriate but also as cost-effective and time-saving for both the institution and the teachers in terms of travel and of physical distribution of materials. However, while the blended learning solution was evidently well-conceived as it sought to attend to an authentic pedagogical and practical need, its implementation was not successful.

The synoptic evaluation described above indicated that an ecology of factors at different levels and from various directions impacted the intervention process and outcome. These were the target learners, the implementation environment, particularly the schools, and factors of a systemic nature, especially policy issues. Within this ecology a number of contradictions were identified, with the help of activity theory (Barab et al., 2002; Jonassen, 2000; Engeström, 1987; Cole \& Engeström, 1993).

In terms of the target group, indications were that while these teachers seemed motivated and interested in BTO, their workplaces did not provide support, culturally or professionally, or resources, particularly ICT resources At an individual level, the teachers lacked adequate ICT skills and confidence so that even where access was reasonably available they would give up if they encountered a technical problem. Lack of participation by others who were part of the online environment also had a discouraging effect. Thus, in some ways participation in BTO was a lonely exercise that required some level of cognitive effort in that it required engagement (Kerrs \& De Witt, 2003). 
With respect to the implementation environment, which was largely the schools of the respective participants, there was a tension between participation in BTO and workplace activity. The school was the implementation environment for BTO in the sense that the teachers were to depend on it for organisational, social, and technical support as they engaged with this learning environment. However, the school activity, whose primary objective is to teach students, opposed the BTO activity, whose primary objective was to train teachers. Thus, the socio-cultural, organisational, and technical environment was constraining to the teachers' participation in BTO. This manifested itself in terms of limited time during the school day or week for the teachers to engage in TPD activities, lack of ICT resources for teachers to use because they are used for teaching purposes, lack of leadership support for TPD activities, and a possible lack of collaborative learning cultures at departmental levels.

On the policy front, there was tension between the existing policies (or at least policy interpretations) regarding INSET for teachers' ICT use in schools and the object of BTO.

Consistent with its policies and guidelines, the MoE uses a model of INSET that follows the acquisition metaphor, which is mainly characterised by a centralised, top-down approach to training. For this reason resources for training are mostly centralized, and ongoing teacher learning in schools is gravely affected. This systemic problem also has an impact on whatever innovations the UB can venture into for INSET as the initiatives are constrained by the reality on the ground. For example, notwithstanding the cultural, organisational, and capacity challenges associated with the INSET programme provider at UB, its guidelines and intentions are clear regarding the intention of vigourosly pursuing, “...the possibility of creating a networking system for mathematics and science departments in schools, education centres and [UB-INSET] via Internet/E-mail..." (University of Botswana, 1997, p. 6). However, this has not been possible due to ICT facility constraints in schools.

To resolve the tensions identified during the implementation of BTO and indeed during any other similar intervention there is perhaps need for the following:

School environments should be supportive of on-going teacher learning in the workplace environment and should manage ICT resources prudently for optimal use not only by students but also by teachers. There should be more availability of these resources across space and time.

Government, particularly the MoE, should create a supportive policy environment matched by funding, resources, capacity building, and support for ICT-supported learning. The MoE should support participatory and localised learning and should institutionalise ICT access and use.

INSET providers, such as the UB, should commit to and provide appropriate training using blended methods, model good ICT practice to teachers, and provide ongoing support for teacher learning in the workplace. Networking among different teacher training stakeholders is also essential. 


\section{Concluding Remarks}

This paper concludes by making the following four observations:

1. Blended learning solutions can be an appropriate approach to increasing access to higher and continuing education in sub-Saharan Africa. These solutions, however, need to be pedagogically grounded and their design should take into account not only the target learners and their immediate implementation environment but also systemic constraints and affordances.

2. Change is needed in the culture of teaching and learning if blended learning solutions, particularly the ICT aspect, are to be succesful. It was evident in this research that the cultural structures and processes of the dominant acquisition model were not in compliance with the notion of online collaborative learning. Therefore there is a need for more balanced training that effectively blends not only delivery systems but also learning perspectives that incorporate, among others, ongoing, situated, participatory, and collaborative approaches.

3. A blend that involves ICT-supported workplace learning is of necessity a collaborative endeavour between at least two players: the training provider and the workplace. This is particularly so in Africa where home Internet access is almost nil and public access is either expensive or not conveniently available for learning purposes. However, while this collaboration is necessary and good, it can also bring tension when the activities of the different collaborators are at variance with each other. For example, in this project the computers in the school were primarily used for teaching purposes and this did not align well with intentions to support the INSET programmes with these facilities. This paradoxical situation could be resolved by initiating fundamental and systemic organisational changes in the teacher education enterprise in order to ensure that technological innovations are successful (Davis, 2002; UNESCO, 2002).

4. While there is rhetorical recognition of the importance of the Internet for TPD in policy documents, there are few, if any, strategies to optimise the use of these already meagre resources. This is an observation that has been widely made in the literature about technology in education in general (Dale et al., 2004; Hammond, 1994; Cuban 2001). Nicol and Watson (2003) identified a gap between the rhetoric about technology transforming learning and the actual reality with teachers and learners on the ground. Closing this gap requires not only skills but also a change in beliefs about ICTs in education. 


\section{References}

Alonso, F., López, G., Manrique, D., \&Viñe, J.M. (2005). An instructional model for web-based e-learning education with a blended learning process approach. British Journal of Educational Technology, 36(2), 217-235.

Ayoo, P. O., \& Lubega, J. (2008). Exploring the implementation of blended learning in a developing country: A case study of Uganda. In J. Aisbett, G. Gibbon, A. Rodrigues, M.J. Kizza, R. Nath, \& G. R. Renardel (Eds.), Strengthening the role of ICT in development: Vol. IV (pp. 133-143). Kampala: Fountain Publishers.

Barab, S., Barnett, M., Yamagata-Lynch, L., Squire, K., \& Keating, T. (2002). Using activity theory to understand the systemic tensions characterizing a technology-rich introductory astronomy course. Mind, Culture, and Activity, 9(2), 76-107.

Bell, P. (2004). On the theoretical breadth of design-based research. Educational Psychologist, $39(4), 243-253$.

Boitshwarelo, B. (2007). Exploring online communities of practice for biology teachers in Botswana. Unpublished doctoral thesis, Deakin University, Melbourne.

Boyle T. (2005). A dynamic, systematic method for developing blended learning. Education, Communication and Information, Special Issue on Blended Learning, 5(3), 221-232.

Brown, A. (1992). Design experiments: Theoretical and methodological challenges in creating complex interventions in classroom settings. The Journal of the Learning Sciences, 2(2), 141-178.

Cole, M., \& Engeström, Y. (1993). A cultural-historical approach to distributed cognition. In G. Salmon (Ed.), Distributed cognitions: Psychological and educational considerations (pp. 1-46). New York: Cambridge University Press.

Collins, A., Joseph, D., \& Bielaczyc, K. (2004). Design research: Theoretical and methodological issues. The Journal of the Instructional Sciences, 13(1), 15-42.

Cuban, L. (2001). Oversold and underused: Computers in the classroom. Cambridge, MA: Harvard University Press.

Dale, R., Robertson, S., \& Shortis, T. (2004). You can't not go with the technological flow, can you? Constructing ICT and teaching and learning. Journal of Computer Assisted Learning, 20, 456-470. 
Davis, N. (2002). Leadership of information technology for teacher education: A discussion of complex systems with dynamic models to inform shared leadership. Journal of Information Technology for Teacher Education, 11(3), 253-272.

Debande, O., \& Ottersten, E. K. (2004). Information and communication technologies: A tool empowering and developing the horizon of the learner. Higher Education Management and Policy, 16(2), 31-61.

Design-Based Research Collective. ( 2003). Design-based research: An emerging paradigm for educational inquiry. Educational Researcher, 32(1), 5-8.

Engeström, Y. (1987). Learning by expanding: An activity-theoretical approach to developmental research. Helsinki: Orienta-Konsultit Oy.

Gess-Newsome, J. (1999). Pedagogical content knowledge: An introduction and orientation. In J. Gess-Newsome \& N. G. Lederman (Eds.), Examining pedagogical content knowledge: Its construct and its implications for science education. Dordrecht: Kluwer Academic Publishers.

Hammond, M. (1994). Measuring the impact of IT on learning. Journal of Computer Assisted Learning, 10, 251-260.

Isaacs, S., Broekman, I., \& Mogale, T. (2004). Contextualising education in Africa: The role of ICTs. In T. James (Ed.), Information and communication technologies for development in Africa, Vol. 3, Networking institutions of learning SchoolNet (pp. 1-23). Ottawa: CODESRIA/IDRC.

Jonassen, D., \& Rohrer-Murphy, L. (1999). Activity theory as a framework for designing constructivist learning environments. Educational Technology Research and Development, 47(1), 61-79.

Jonassen, D. H. (2000). Revisiting activity theory as a framework for designing student-centred learning environments. In D. H. Jonassen \& S. M. Land (Eds.), Theoretical foundations of learning environments (pp. 89-122). Mahwah: Lawrence Erlbaum Associates.

Kerres, M., \& De Witt C. (2003). A didactical framework for the design of blended learning arrangements. Journal of Educational Media, 28, (2-3).

Kok D., \& Merz C. (2004). Africa drive project-innovative teacher development in South Africa. Proceedings of IEEE International Conference on Advanced Learning Technologies, 30.

Kruger, C. G., \& Spamer, E. J. (2006, September). Teacher upgrading through distance education in a South African context. Paper presented at the International Conference on Distance Education, Rio de Janeiro. 
Leary, J., \& Berge Z. (2007). Successful distance education programs in sub-Saharan Africa. Turkish Online Journal of Distance Education, 8(2), Article 12.

Lewin, K. M. (2000). New technologies and knowledge acquisition and use in developing countries. Compare, 30(3), 313-321.

Mackintosh, W. (2005). Can you lead from behind? Critical reflections on the rhetoric of elearning, open distance learning and ICTs for development in sub-Saharan Africa (SSA). In A. A. Carr-Chellman (Ed.), Global perspectives on e-learning: Rhetoric and reality (pp. 222-240). Thousand Oaks, California: SAGE Publications.

Ministry of Communication Science and Technology (MCST). (2005). Draft national information and communications technology policy. Retrieved December, 2005, from http://www.maitlamo.gov.bw/docs/draft-policies/ict_policy_draft_jan_2005.pdf

Mokaeya, B. (2005). The development of distance education in Botswana. The Quarterly Review of Distance Education, 6(3).

Nichol J., \& Watson, K. (2003). Rhetoric and reality- the present and future of ICT in education. British Journal of Educational Technology, 34(1).

Paterson A. (2005). Changing the 'landscape' of learning: The future of blended learning provision in newly merged South African higher education institutions. International Journal of Education and Development using Information and Communication Technology (IJEDICT), 1(2), 25-41.

Republic of Botswana. (1994). The revised national policy on education. Gaborone: Government of Botswana.

Sagna, O. (2005). Lifelong learning in the African context: A practical example from Senegal. In C. McIntosh \& Z. Varoglu (Eds.), Perspectives on distance education: Lifelong \& distance higher education (pp. 51-62). Vancouver, British Columbia and Paris: Commonwealth of Learning/UNESCO.

Salmon, G. (2002). E-tivities: The key to active online learning. London: Kogan Page.

Schachter, L., Pence, A., Zuckernick, A., \& Roberts J. (2005). Distance learning in Africa: From brain drain to brain gain. In M. Beaudoin (Ed.), Pespectives in the future of higher education in digital age (pp. 165-186). Hauppage, NY: Nova Science Publishers.

Seleka, G.G., Mgaya, K.V., \& Sechaba, M.N. (2006). The use of various ICT's in blended collaborative learning at the University of Botswana. Retrieved March 2009, from, 
http://emerge2006.net/connect/site/UploadWSC/emerge2006/file76/WebCT_Vs_FOB_W ebsite emerge2006.pdf

Selinger, M. (2002, July). Education and skills development in sub-Saharan Africa. Paper presented at the ASET conference, Melbourne.

Shrestha, G. (2000). Utilization of information and communications technology for education in Africa. Addis Ababa: UNESCO, IICBA.

Shulman, L. S. (1986). Those who understand: Knowledge growth in teaching. Educational Researcher, 15, 4-14.

Thijs, A. M. (1999). Supporting science curriculum reform in Botswana: The potential of peer coaching. University Of Twente, Enschede.

UNESCO. (2002). Information and communications technologies in teacher education: A planning guide. Paris: Division of Higher Education, UNESCO.

University of Botswana. (1997). A policy document on the institutionalisation of UB-INSET.

University of Botswana. (2004a). About the Centre for Academic Development. Retrieved March, 2005, from www.ub.bw/department/centres/CAD_cfm

University of Botswana. (2004b). Vision and mission. Retrieved March, 2005, from www.ub.bw/about/vision.cfm

Unwin, T. (2005). Towards a framework for the use of ICT in teacher training in Africa. Open Learning, 20(2), 113-129.

Yamagata-Lynch, L. C. (2002). Using activity theory as an analytic lens for examining technology professional development in schools. Mind, Culture, and Activity, 10(2), 100119.

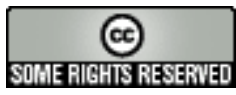

